\title{
INTERNATIONAL RISK SHARING IS BETTER THAN YOU THINK (OR EXCHANGE RATES ARE MUCH TOO SMOOTH)
}

\author{
Michael W. Brandt \\ John H. Cochrane \\ Pedro Santa-Clara \\ Working Paper 8404 \\ http://www.nber.org/papers/w8404
NATIONAL BUREAU OF ECONOMIC RESEARCH 1050 Massachusetts Avenue
Cambridge, MA 02138
July 2001

We thank Richard Roll for helpful comments. Michael W. Brandt gratefully acknowledges financial support from the Weiss Center for International Financial Research at the Wharton School, and John H. Cochrane gratefully acknowledges financial support from the Graduate School of Business and from an NSF grant administered by the NBER. The views expressed herein are those of the authors and not necessarily those of the National Bureau of Economic Research.

(C) 2001 by Michael W. Brandt, John H. Cochrane and Pedro Santa-Clara. All rights reserved. Short sections of text, not to exceed two paragraphs, may be quoted without explicit permission provided that full credit, including (C) notice, is given to the source. 
International Risk Sharing is Better Than You Think

(or Exchange Rates are Much Too Smooth)

Michael W. Brandt, John H. Cochrane and Pedro Santa-Clara

NBER Working Paper No. 8404

July 2001

JEL No. G12, G15, F31

\begin{abstract}
Exchange rates depreciate by the difference between the domestic and foreign marginal utility growths. Exchange rates vary a lot, as much as $10 \%$ per year. However, equity premia imply that marginal utility growths vary much more, by at least $50 \%$ per year. This means that marginal utility growths must be highly correlated across countries -- international risk sharing is better than you think. Conversely, if risks really are not shared internationally, exchange rates should vary more than they do -- exchange rates are much too smooth. We calculate an index of international risk sharing that formalizes this intuition in the context of both complete and incomplete capital markets. Our results suggest that risk sharing is indeed very high across several pairs of countries.
\end{abstract}

Michael W. Brandt

The Wharton School

University of Pennsylvania

2300 Steinberg Hall-Dietrich Hall

Philadelphia, PA 19104

and NBER

brandtm@wharton.upenn.edu

http://brandt.wharton.upenn.edu/

John H. Cochrane

Graduate School of Business

University of Chicago

1101 East 58th Street

Chicago, IL 60637

and NBER

john.cochrane@gsb.uchicago.edu

http://gsbwww.uchicago.edu/fac/john.cochrane/research/Papers/

Pedro Santa-Clara

Anderson Graduate School of Management

UCLA

110 Westwood Plaza

Los Angeles, CA 90095

pedro.santa-clara@anderson.ucla.edu

http://www.personal.anderson.ucla.edu/pedro.santa-clara/ 


\section{Introduction}

Exchange rates $e_{t+1}$ are linked to domestic and foreign marginal utility growths or discount factors $m_{t+1}^{d}$ and $m_{t+1}^{f}$ by the equation: ${ }^{1}$

$$
\ln \frac{e_{t+1}}{e_{t}}=\ln m_{t+1}^{f}-\ln m_{t+1}^{d} .
$$

Exchange rates vary a lot, as much as $10 \%$ per year. However, following the calculations of Hansen and Jagannathan (1991), equity premia imply that marginal utility growths vary much more, by at least $50 \%$ per year. Equation (1) then tells us that domestic and foreign marginal utility growths must be highly correlated across countries - international risk sharing is better than you think. Conversely, if risks were not shared internationally - if marginal utility growths were uncorrelated across countries - it tells us that exchange rates should vary by $\sqrt{2} \times 0.5 \%=71 \%$ or more - exchange rates are much too smooth.

To formalize this idea, we compute the following index of international risk sharing: ${ }^{2}$

$$
1-\frac{\sigma^{2}\left(\ln m_{t+1}^{f}-\ln m_{t+1}^{d}\right)}{\sigma^{2}\left(\ln m_{t+1}^{f}\right)+\sigma^{2}\left(\ln m_{t+1}^{d}\right)}=1-\frac{\sigma^{2}\left(\ln \frac{e_{t+1}}{e_{t}}\right)}{\sigma^{2}\left(\ln m_{t+1}^{f}\right)+\sigma^{2}\left(\ln m_{t+1}^{d}\right)} .
$$

The numerator measures how different marginal utility growths are in the two countries how much risk is not shared. The denominator measures the volatility of marginal utility growths in the two countries - how much risk there is to share. A $10 \%$ exchange rate volatility and a $50 \%$ marginal utility growth volatility in each country imply a risk sharing index of $1-0.1^{2} /\left(2 \times 0.5^{2}\right)=0.98$. A lot of risk is shared.

Our index is not quite the same as a correlation. Like a correlation, it is equal to one if $\ln m^{f}=\ln m^{d}$. Also, the index is equal to zero if $\ln m^{f}$ and $\ln m^{d}$ are uncorrelated, and it is equal to minus one if (pathologically) $\ln m^{f}=-\ln m^{d}$. However, perfect risk sharing requires that the domestic and foreign marginal utility growths are equal, not just perfectly correlated. $\ln m^{f}=2 \times \ln m^{d}$ is a violation of risk sharing just as much as if marginal utility growths are uncorrelated, and we want a measure of risk sharing to detect violations of scale as well as of correlation. If $\ln m^{f}=2 \times \ln m^{d}$, our index is 0.8 .

\footnotetext{
${ }^{1}$ We discuss this equation in detail below, including the case of incomplete markets. For now, you can regard it as a change of units from the marginal utility of domestic goods to the marginal utility of foreign goods. Among many others, Backus, Foresi, and Telmer (2001), Brandt and Santa-Clara (2001), Nielsen and Saá-Requejo (1993), and Saá-Requejo (1993) exploit this equation to relate the dynamics of the exchange rate to the dynamics of the domestic and foreign discount factors.

${ }^{2}$ We connect $\operatorname{logs}$ and levels in a continuous time formulation below. In this formulation, the variances that enter the index can be interpreted as variances of either log changes or percent changes.
} 


\subsection{Interpreting the Calculation}

\section{Transport Costs}

Risk sharing requires frictionless goods markets. The container ship is as important as 24 hour trading. ${ }^{3}$ Suppose that Earth trades with Mars in complete and frictionless capital markets. If Mars enjoys a positive productivity shock, Earth-based owners of Martian assets rejoice in anticipation of their payoffs. But trade with Mars is still impossible, so the real exchange rate between Mars and Earth must adjust exactly to offset any net payoff. In the end, Earth marginal utility growth must reflect Earth resources, and the same for Mars. If the underlying shocks are uncorrelated, the exchange rate variance is the sum of the variances of Earth and Mars marginal utility growth, and we measure a zero risk sharing index.

At the other extreme, if there is costless trade between two countries, and the real exchange rate is therefore constant, marginal utilities can move in lockstep. With constant exchange rates, we measure a perfect risk sharing index of one.

Actual economies produce a mix of tradeable and non-tradeable goods, and transport costs vary by good and country-pair. Thus, actual economies lie somewhere between the two extremes. If there is a positive shock in one country, asset holdings by the other countries should lead to an outflow of goods. But, it is costly to ship goods, and those costs increase with the volume being shipped. Therefore, real exchange rates move and their fluctuations blunt risk sharing. Our index lies between zero and one. Where it lies between zero and one is the interesting empirical question.

\section{Incomplete Markets}

Incomplete asset markets are the second reason that risk sharing may be imperfect. If no state-contingent payments are promised, marginal utilities can diverge across countries, even without transport costs and a constant exchange rate.

Also, with incomplete asset markets, the discount factors $m_{t+1}^{d}$ and $m_{t+1}^{f}$ that we can recover from asset market data are not unique. For example, given a domestic discount factor $m_{t+1}^{d}$, any discount factor of the form $m_{t+1}^{d}+\varepsilon_{t+1}$ also prices all of the assets, where $\varepsilon_{t+1}$ is any random variable uncorrelated with asset payoffs. ${ }^{4}$ Equation (1) does not hold for arbitrary pairs of domestic and foreign discount factors.

\footnotetext{
${ }^{3}$ Obsfeld and Rogoff (2000) emphasize the importance of transport costs for understanding a wide range of puzzles in international economics.

${ }^{4}$ Precisely, $\varepsilon_{t+1}$ is any random variable with $\mathrm{E}_{t}\left(\varepsilon_{t+1} x_{t+1}^{d}\right)=0$ and $\mathrm{E}_{t}\left(\varepsilon_{t+1} \frac{e_{t+1}}{e_{t}} x_{t+1}^{f}\right)=0$, where $x^{d}$ and $x^{f}$ denote the payoffs of the domestic and foreign assets, respectively.
} 
To think about incomplete markets and multiple discount factors, start by considering a single economy with many agents. In an incomplete market, individuals' marginal utility growths may not be equal. However, the projection of each individual's marginal utility growth on the space of asset payoffs should still be the same. ${ }^{5}$ Individuals should use the available assets to share risks as much as possible. For example, we should not see one consumer heavily invested in tech stocks and another in blue chip stocks, so that one is more affected than the other when tech stocks fall - unless differences in preferences or non-market risks translate the different asset payoffs into equal shocks to marginal utility growth.

With this example in mind, we evaluate equations (1) and (2) using the unique discount factors $m_{t+1}^{d}$ and $m_{t+1}^{f}$ that are in the space of domestic and foreign asset payoffs (evaluated in units of domestic and foreign goods, respectively), and hence are the projection of any possible domestic and foreign discount factor on to the relevant spaces of asset payoffs. These are also the minimum-variance domestic and foreign discount factors, respectively. We show that equation (1) continues to hold with this particular choice of discount factors. Our index of international risk sharing thus answers the questions: How effectively do countries use existing asset markets to share risks? How much do exchange rate changes blunt the effectiveness of risk sharing using existing asset markets?

Overall risk sharing can be better or worse than the result of our calculation, so our calculation does not yield an upper or lower bound. If the additional risks (the residuals in regressions of marginal utility growth on asset payoffs) are perfectly correlated across countries, the numerator of the index (2) does not change, but the denominator increases. In this case, true risk sharing is better than indicated by our index. Omitted assets are the most likely source of additional positively correlated risks. Additional assets make discount factors more volatile, but typically do so in the same way for domestic and foreign investors. Additional common shocks - such as international business cycles - have the same effect.

If the additional risks are uncorrelated across countries, true risk sharing is lower than our calculation. In this case, both the numerator and denominator of the index (2) increase by the same amount. As the additional uncorrelated risks increase in magnitude and ultimately swamp the exchange rates and discount factors that we measure, the true risk sharing index declines to zero. Quantitatively, though, additional risks have to be on the same order as the

\footnotetext{
${ }^{5}$ The projection is the fitted value of a regression of marginal utility growth on the asset payoffs. It is the "mimicking portfolio" for marginal utility. The prediction that this projection should be equal across individuals can be derived from the individual's first order conditions. Each individual's marginal utility growth $m^{i}$ satisfies $p_{t}=\mathrm{E}_{t}\left(m_{t+1}^{i} x_{t+1}\right)$, and thus (since residuals are orthogonal to fitted values) $p_{t}=\mathrm{E}_{t}\left[\operatorname{proj}\left(m_{t+1}^{i} \mid X\right) x_{t+1}\right]$ where $X$ denotes the payoff space of all traded assets. There is a unique discount factor $x^{*} \in X$ such that $p_{t}=E_{t}\left(x_{t+1}^{*} x_{t+1}\right)$ for all $x \in X$ Since this discount factor is unique, $\operatorname{proj}\left(m_{t+1}^{i} \mid X\right)=x^{*}$ is the same for all individuals. See Cochrane (2001) for elaboration on this theme.
} 
$50 \%$ volatility of the minimum variance discount factor to seriously affect our risk sharing index. It is difficult enough to understand the $50 \%$ volatility of the minimum variance discount factor; do we really believe that there are other country risks, orthogonal to asset market returns, that add up to an additional 50\% volatility of marginal utility growth?

In sum, with incomplete asset markets and no strong information about the correlation of unspanned risks across countries, the proportion of true risks that are shared can be higher or lower than our calculation. For this reason, we stick with the above interpretation of risk sharing through existing capital markets, rather than try to read the index as a bound on the fraction of total risks that are shared. ${ }^{6}$

\subsection{Consumption-Based Estimates and Home Bias}

\section{Poor Risk Sharing in Consumption Data}

The conclusion that almost all risk is shared internationally lies in stark contrast to the picture painted by consumption data. Consumption growth is poorly correlated across countries, and this apparently poor international risk sharing is one of the major puzzles of international economics. ${ }^{7}$ In addition, it is not very volatile, so when consumption growth is multiplied by reasonable risk aversion to produce marginal utility growth, consumptionbased models cannot produce the observed volatility of the exchange rate via equation (1), just as they cannot reproduce the observed equity premium. This observation has lead some authors to conclude that exchange rates are much too volatile. ${ }^{8}$

The difference, of course, is that we measure marginal utility growth from asset markets rather than from consumption data. We measure marginal utility growth directly, rather than from consumption or portfolio choices via a utility function. Asset markets and consumption data (plus a utility function and parameters) give quite different pictures of marginal utility growth. Based on asset data, it appears that there is a lot of risk $\left(\sigma\left(\ln m^{d}\right)\right.$ and $\sigma\left(\ln m^{f}\right)$ are large) and that risk is shared surprisingly well across countries $\left(m^{d}\right.$ and $m^{f}$ move together). Alternatively, exchange rates are surprisingly smooth $(\sigma(\Delta \ln e)$ is small).

\footnotetext{
${ }^{6}$ By using an upper limit on the volatility of the discount factors in the denominator of the index (2), in the style of Cochrane and Saá-Requejo (1999), one can obtain a lower bound on overall risk sharing, but we do not pursue this calculation here.

${ }^{7}$ Important contributions to this literature include Backus, Kehoe, and Kydland (1992), Backus and Smith (1993), Brennan and Solnik (1989), Lewis (1996, 2000), Tesar (1993).

${ }^{8}$ See Flood and Rose (1995), Mark (1985), Meese and Rogoff (1983), Obsfeld and Rogoff (2000), and Rogoff (1999). Perfect insurance is also rejected within a country, see for example Cochrane (1991) and Mace (1991). However, it is quite likely that aggregate consumption is better insured across countries using stock markets than idiosyncratic income is insured within countries.
} 
Based on consumption data and power utility, in contrast, it appears that there is little risk, that risk is poorly shared, and exchange rates are surprisingly volatile.

Our aim in this paper is only to document the asset-market view of exchange rates and risk sharing, not to reconcile it with consumption data. Even in a single-country setting, reconciling the asset-market view - a high equity premium and large discount factor volatility - with consumption data seems to require dramatic departures from the conventional power utility setup (e.g., habits as in Campbell and Cochrane, 1999, or countercyclical idiosyncratic risk as in Constantinides and Duffie, 1996). Reconciling the asset-market view with the smoothness and poor correlation of consumption and other quantity data is likely to require similarly large departures from separable power utility.

\section{Home Bias Puzzle}

The home bias puzzle is that US investors largely hold US securities, Japanese investors largely hold Japanese securities, and so forth. ${ }^{9}$ Typical investors are quite far from holding a uniform world market portfolio that one might imagine underlies perfect risk sharing.

Exchange rate volatility - induced by nontraded goods - is a natural source of home bias. Returning to the example of Earth and Mars, once Earth-based investors understand that exchange rate movements will offset any gains from holding Martian securities, their optimal portfolios may ignore those securities. While this reasoning helps to understand the home bias in consumption-based models that produce little variation in marginal utility growth, it has not yet been successful in quantitatively explaining the puzzle. ${ }^{10}$

Related, exchange rate volatility induces some home bias in mean-variance optimal portfolio calculations. ${ }^{11}$ The exchange rate is almost as volatile as stock returns, and it tends to be poorly correlated with both domestic and foreign stock markets. This makes foreign stocks less desirable to the domestic investor relative to domestic stocks, and vice versa for the foreign investor. Unfortunately, the mean-variance optimal degree of home bias is a great deal lower than the observed home bias, leaving the puzzle largely unresolved.

\footnotetext{
${ }^{9}$ French and Poterba (1991) observe that Americans held $94 \%$ of their equity wealth in the US stock market. The analogous figure for Japan was $98 \%$. Baxter and Jermann (1997) point out that since human capital is domestic, adding labor income risk actually worsens the puzzle. Tesar and Werner (1995) show that foreign portfolios turned over much faster than domestic portfolios, and argue that this suggests that transactions costs do not drive the home bias. See Lewis (1999) for a survey of the home bias puzzle. Interestingly, there is also a small home bias at home. Coval and Moskowitz (1999) find that fund managers hold stocks of companies that are on average somewhat closer to them than the market as a whole.

${ }^{10}$ In fact, Baxter, Jermann, and King (1995) show that nontradable goods cannot explain the puzzle quantitatively in the context of a multi-country general equilibrium model.

${ }^{11}$ See for example, Black and Litterman (1992).
} 
The home bias puzzle does not conflict with our calculation. Our risk sharing index is based on a direct measure of marginal utility growth. The home bias puzzle refers to an optimal portfolio calculation for a specific utility function, underlying income process, and asset return process. It is quite possible to see large amounts of risk sharing in marginal utility growth, but still to be puzzled by the underlying economic model that generates it and the portfolio positions that support it. For example, if the underlying income shocks are highly correlated, or if risk sharing is achieved by other means (e.g., government transfers, direct payments to relatives abroad, other assets), or if preferences are not the simple oneperiod quadratic utility over wealth, we can see volatile and highly correlated marginal utility growths despite very little asset cross-holding.

The minimum variance discount factor is the projection of marginal utility growth onto the space of asset payoffs. It is not itself the optimal portfolio or the "market" portfolio. The minimum variance discount factor is proportional to the minimum second-moment portfolio, which is on the bottom of the mean-variance frontier. (See Cochrane, 2001.) In a meanvariance setting, the optimal, tangency, and market portfolios are all on the top of the meanvariance frontier. Domestic and foreign discount factors can therefore be highly correlated even if the optimal portfolios that help generate the marginal utilities are not.

Another difference between our calculation and a portfolio problem is that the two key ingredients to our risk sharing index are the mean stock returns and the variance of the exchange rate, since the mean stock returns drive the volatility of the discount factors. In thinking about risk sharing from a portfolio perspective, it is more natural to focus on the correlation of international stock returns. The variance and correlation of stock returns are only of secondary importance to our risk sharing calculation (they help to determine the loadings of the projection).

We assume that investors can buy stocks internationally - their first-order conditions for international stock purchases are satisfied. (This assumption is implicit in the home bias puzzle because otherwise the home bias is hardly puzzling.) It does not matter for our calculation whether they actually $d o$ so - whether their optimal portfolios contain large positions in foreign assets or not. In the language of the international finance literature, we assume that the capital market are fully integrated. Dumas, Harvey, and Ruiz (2000) find that this is consistent with the data for the large countries that we study. 


\section{Calculation}

We adopt a continuous time formulation. While the notation is a little more tedious, this allows us to translate more easily between logs and levels.

\subsection{Discount factors and the risk-sharing index}

We first describe how to recover the minimum-variance discount factor from asset markets in general, and then we specialize the discussion to our international setting.

Suppose that a vector of assets has the following excess return process: ${ }^{12}$

$$
d R=\mu d t+d z \quad \text { with } \quad \mathrm{E}\left(d z d z^{\prime}\right)=\Sigma d t .
$$

There is also a riskfree asset:

$$
\frac{d B}{B}=r d t
$$

With this notation, the discount factor:

$$
\frac{d \Lambda}{\Lambda}=-r d t-\mu^{\prime} \Sigma^{-1} d z
$$

prices the assets, i.e., it satisfies the first order conditions:

$$
-r d t=\mathrm{E}\left(\frac{d \Lambda}{\Lambda}\right) \quad \text { and } \quad \mu d t=-\mathrm{E}\left(\frac{d \Lambda}{\Lambda} d R\right)
$$

In this formulation, $d \Lambda / \Lambda$ plays the role of $m$ in the introduction. Equation (5) shows why mean asset returns determine the volatility of marginal utility growth. Holding constant $\Sigma$, the higher $\mu$ is, the more $d \Lambda / \Lambda$ loads on the shocks $d z$, and the more volatile is $d \Lambda / \Lambda$.

We can add to this discount factor any shocks $d w$ that are uncorrelated with $d z$, and this has no effect on the pricing relationship (6). Since $d w$ and $d z$ are uncorrelated, discount factors so formed will have greater variance. This implies that the discount factor (5) is the unique discount factor formed as a linear combination of shocks to assets $d z$. It is the minimum-variance discount factor, and it is the projection of any valid discount factor on to the space spanned by the shocks $d z$.

\footnotetext{
${ }^{12} \mathrm{An}$ excess return is the difference between any two value processes, e.g., $d R=d S / S-d V / V$. We often use a riskfree asset for $d V / V$, but this is not necessary.
} 
We can construct the log discount factor, required in equations (1) and (2), via Ito's lemma:

$$
d \ln \Lambda=\frac{d \Lambda}{\Lambda}-\frac{1}{2} \frac{d \Lambda^{2}}{\Lambda^{2}}=-\left(r+\frac{1}{2} \mu^{\prime} \Sigma^{-1} \mu\right) d t-\mu^{\prime} \Sigma^{-1} d z
$$

and then evaluate its variance as:

$$
\frac{1}{d t} \sigma^{2}(d \ln \Lambda)=\mu^{\prime} \Sigma^{-1} \mu
$$

We now specialize the formulas to our international context. To find the domestic and foreign discount factors that price domestic and foreign stocks and bonds, we simply need to express the appropriate vectors of excess returns $\mu$ and covariance matrices $\Sigma$. We write the real returns on the domestic riskfree asset $B^{d}$, domestic stocks $S^{d}$, exchange rate $e$ (in units of foreign goods/domestic goods), foreign riskfree asset $B^{f}$, and foreign stocks $S^{f}$ as:

$$
\begin{gathered}
\frac{d B^{d}}{B^{d}}=r^{d} d t, \quad \frac{d S^{d}}{S^{d}}=\theta^{d} d t+d z^{d}, \\
\frac{d e}{e}=\theta^{e} d t+d z^{e} \\
\frac{d B^{f}}{B^{f}}=r^{f} d t, \quad \frac{d S^{f}}{S^{f}}=\theta^{f} d t+d z^{f} .
\end{gathered}
$$

We collect the shocks in a vector $d z$ and write the covariance matrix as: ${ }^{13}$

$$
d z=\left[\begin{array}{c}
d z^{d} \\
d z^{e} \\
d z^{f}
\end{array}\right] \text { and } \quad \Sigma=\frac{1}{d t} \mathrm{E}\left(d z d z^{\prime}\right)=\left[\begin{array}{ccc}
\Sigma^{d d^{\prime}} & \Sigma^{d e} & \Sigma^{d f^{\prime}} \\
\Sigma^{e d^{\prime}} & \Sigma^{e e} & \Sigma^{e f^{\prime}} \\
\Sigma^{f d^{\prime}} & \Sigma^{f e} & \Sigma^{f f^{\prime}}
\end{array}\right]
$$

Next, we find the excess returns in terms of this notation. The excess domestic stock return is simply:

$$
d R^{d} \equiv \frac{d S^{d}}{S^{d}}-\frac{d B^{d}}{B^{d}}=\left(\theta^{d}-r^{d}\right) d t+d z^{d}
$$

To invest in the foreign riskfree bond, the domestic investor also faces currency risk. Hence, the excess return is:

$$
\frac{d\left(e B^{f}\right)}{e B^{f}}-\frac{d B^{d}}{B^{d}}=\frac{d e}{e}+r^{f} d t-r^{d} d t=\left(\theta^{e}+r^{f}-r^{d}\right) d t+d z^{e} .
$$

\footnotetext{
${ }^{13}$ We use the notation $\Sigma^{d d^{\prime}}$ etc. because there may be several risky assets in each economy.
} 
The foreign excess return to foreign stocks is:

$$
d R^{f} \equiv \frac{d S^{f}}{S^{f}}-\frac{d B^{f}}{B^{f}}=\left(\theta^{f}-r^{f}\right) d t+d z^{f}
$$

but we need the domestic counterpart to this foreign excess return. Accounting for exchange risk, the domestic returns to holding a foreign stock and riskfree asset are $d\left(e S^{f}\right) / e S^{f}$ and $d\left(e B^{f}\right) / e B^{f}$ respectively. Thus, the corresponding domestic excess return is: ${ }^{14}$

$$
\begin{aligned}
\frac{d\left(e S^{f}\right)}{e S^{f}}-\frac{d\left(e B^{f}\right)}{e B^{f}} & =\frac{d S^{f}}{S^{f}}-\frac{d B^{f}}{B^{f}}+\frac{d e}{e}\left(\frac{d S^{f}}{S^{f}}-\frac{d B^{f}}{B^{f}}\right) \\
& =\left(1+\frac{d e}{e}\right)\left(\frac{d S^{f}}{S^{f}}-\frac{d B^{f}}{B^{f}}\right) \\
& =\left(1+\frac{d e}{e}\right) d R^{f} \\
& =\left(1+\theta^{e} d t+d z^{e}\right)\left[\left(\theta^{f}-r^{f}\right) d t+d z^{f}\right] \\
& =\left(\theta^{f}-r^{f}\right) d t+d z^{e} d z^{f}+d z^{f} \\
& =\left(\theta^{f}-r^{f}+\Sigma^{e f}\right) d t+d z^{f} .
\end{aligned}
$$

Stacking the three excess returns (11), (12), and (14), the vector of mean excess returns to a domestic investor is:

$$
\mu^{d}=\left[\begin{array}{c}
\theta^{d}-r^{d} \\
\theta^{e}+r^{f}-r^{d} \\
\theta^{f}-r^{f}+\Sigma^{e f}
\end{array}\right]
$$

and the covariance matrix of excess returns is just $\Sigma$. It follows that the minimum-variance domestic discount factor is:

$$
\frac{d \Lambda^{d}}{\Lambda^{d}}=-r^{d} d t-\mu^{d \prime} \Sigma^{-1} d z
$$

By Ito's lemma we then have:

$$
d \ln \Lambda^{d}=-\left(r^{d}+\frac{1}{2} \mu^{d \prime} \Sigma^{-1} \mu^{d}\right) d t-\mu^{d \prime} \Sigma^{-1} d z
$$

and

$$
\frac{1}{d t} \sigma^{2}\left(d \ln \Lambda^{d}\right)=\mu^{d \prime} \Sigma^{-1} \mu^{d}
$$

\footnotetext{
${ }^{14}$ Alternatively, we could define an excess return for the domestic investor in the foreign stock as $\frac{d e S^{f}}{e S^{f}}-\frac{d B^{d}}{B^{d}}$.
} 
We derive the foreign discount factor analogously. The foreign discount factor must price the foreign stocks, the domestic riskfree asset, and the domestic stocks. This is symmetric to the domestic discount factor, except for Ito terms. Again, all we need is to find the relevant $\mu$ and $\Sigma$. The foreign excess return from holding foreign stocks is already given by equation (13). The foreign excess return from borrowing at the domestic interest rate and investing at the foreign interest rate is: ${ }^{15}$

$$
\begin{aligned}
-\frac{d(1 / e)}{(1 / e)}-\left(r^{d}-r^{f}\right) d t & =\left(r^{f}-r^{d}\right) d t+\frac{d e}{e}-\frac{d e^{2}}{e^{2}} \\
& =\left(\theta^{e}+r^{f}-r^{d}-\Sigma^{e e}\right) d t+d z^{e} .
\end{aligned}
$$

The foreign returns to holding a domestic stock and risky bond are $d\left(S^{d} / e\right) /\left(S^{d} / e\right)$ and $d\left(B^{d} / e\right) /\left(B^{d} / e\right)$, respectively. Therefore, the excess return to a foreign investor is:

$$
\begin{aligned}
\frac{d\left(S^{d} / e\right)}{S^{d} / e}-\frac{d\left(B^{d} / e\right)}{B^{d} / e} & =\left(\frac{d S^{d}}{S^{d}}-\frac{d e}{e}+\frac{d e^{2}}{e^{2}}-\frac{d e}{e} \frac{d S^{d}}{S^{d}}\right)-\left(\frac{d B^{d}}{B^{d}}-\frac{d e}{e}+\frac{d e^{2}}{e^{2}}-\frac{d e}{e} \frac{d B^{d}}{B^{d}}\right) \\
& =\frac{d S^{d}}{S^{d}}-\frac{d B^{d}}{B^{d}}-\frac{d e}{e}\left(\frac{d S^{d}}{S^{d}}-\frac{d B^{d}}{B^{d}}\right) \\
& =\left(1-\frac{d e}{e}\right) d R^{d} \\
& =\left(1-\theta^{e} d t-d z^{e}\right)\left[\left(\theta^{d}-r^{d}\right) d t+d z^{d}\right] \\
& =\left(\theta^{d}-r^{d}\right) d t-d z^{e} d z^{d}+d z^{d} \\
& =\left(\theta^{d}-r^{d}-\Sigma^{e d}\right) d t+d z^{d} .
\end{aligned}
$$

Stacking the excess returns (13), (19), and (20), the vector of mean excess returns faced by foreign investors is:

$$
\mu^{f}=\left[\begin{array}{c}
\theta^{d}-r^{d}-\Sigma^{e d} \\
\theta^{e}+r^{f}-r^{d}-\Sigma^{e e} \\
\theta^{f}-r^{f}
\end{array}\right]
$$

and the covariance matrix is again $\Sigma$. Thus, we can write the foreign discount factor

\footnotetext{
${ }^{15}$ Note that $d \frac{1}{e}=-\frac{1}{e^{2}} d e+\frac{1}{e^{3}} d e^{2}$ and $\frac{d(1 / e)}{1 / e}=-\frac{d e}{e}+\frac{d e^{2}}{e^{2}}$. We write the foreign excess return slightly unconventionally as the return to borrowing domestically to invest in foreign assets. This specification highlights the symmetry between domestic and foreign investors. Of course, the sign of an excess return makes no difference to the volatility of the discount factor (see equation (8)).
} 
analogously to equation (16) as:

$$
\frac{d \Lambda^{f}}{\Lambda^{f}}=-r^{f} d t-\mu^{f \prime} \Sigma^{-1} d z
$$

or

$$
d \ln \Lambda^{f}=-\left(r^{f}+\frac{1}{2} \mu^{f \prime} \Sigma^{-1} \mu^{f}\right) d t-\mu^{f \prime} \Sigma^{-1} d z .
$$

Our risk sharing index in equation (2) is therefore:

$$
1-\frac{\sigma^{2}\left(d \ln \Lambda^{d}-d \ln \Lambda^{f}\right)}{\sigma^{2}\left(d \ln \Lambda^{d}\right)+\sigma^{2}\left(d \ln \Lambda^{f}\right)}=1-\frac{\Sigma^{e e}}{\mu^{d /} \Sigma^{-1} \mu^{d}+\mu^{f \prime} \Sigma^{-1} \mu^{f}} .
$$

\subsection{Incomplete Markets}

When markets are incomplete, the minimum-variance discount factors recovered from asset markets are not the only possible ones. We can always scale the minimum-variance domestic marginal utility $\Lambda^{d}$ by a positive martingale and obtain another candidate for domestic marginal utility:

$$
\Lambda^{d *}=\Lambda^{d} \eta^{d}
$$

where:

$$
\frac{d \eta^{d}}{\eta^{d}}=d w^{d} \quad \text { with } \quad \mathrm{E}\left(d w^{d} d z\right)=0
$$

The resulting marginal utility growth (by Ito's lemma): ${ }^{16}$

$$
\frac{d \Lambda^{d *}}{\Lambda^{d *}}=\frac{d \Lambda^{d}}{\Lambda^{d}}+\frac{d \eta^{d}}{\eta^{d}}=\frac{d \Lambda^{d}}{\Lambda^{d}}+d w^{d}
$$

satisfies the first-order conditions (6) and is hence a valid discount factor. We therefore need to think more carefully about what our calculation for variance-minimizing discount factors says about marginal utility growth with incomplete markets. This section formalizes the discussion in the introduction.

\footnotetext{
${ }^{16}$ Notice that we increase the riskiness of marginal utility by multiplying it by a positive martingale. Through Ito's lemma, this amounts to adding zero-mean noise to minimum-variance marginal utility growth.
} 
Minimum-Variance Discount Factors Satisfy the Identity

Given $a$ domestic marginal utility $\Lambda^{d}$, the choice $\Lambda^{f}=k e \Lambda^{d}$ (with any constant $k$ ) prices the foreign assets. But not all foreign discount factors satisfy this relation. If one does, another formed by adding $d w$ does not. Thus, the basic identity: $\Lambda^{f}=k e \Lambda^{d}$ and its key implication

$$
d \ln e=d \ln \Lambda^{f}-d \ln \Lambda^{d}
$$

that allows us to use exchange rates to measure the difference between the domestic and foreign discount factors, does not hold for arbitrary choices of the discount factors.

Fortunately, the basic identity $\Lambda^{f}=k e \Lambda^{d}$ and equation (28) do hold for the minimumvariance discount factors. To see this result, note from the definitions (15) and (21) that we can write:

$$
\mu^{f}=\mu^{d}-\left[\begin{array}{c}
\Sigma^{e d} \\
\Sigma^{e e} \\
\Sigma^{e f}
\end{array}\right]=\mu^{d}-\Sigma^{e}
$$

where $\Sigma^{e}$ denotes the middle column of $\Sigma$. Thus, we can relate the domestic and foreign minimum-variance discount factors by:

$$
\begin{aligned}
\frac{d \Lambda^{f}}{\Lambda^{f}} & =\frac{d \Lambda^{d}}{\Lambda^{d}}+\left(r^{d}-r^{f}\right) d t+\Sigma^{e \prime} \Sigma^{-1} d z \\
& =\frac{d \Lambda^{d}}{\Lambda^{d}}+\left(r^{d}-r^{f}\right) d t+d z^{e}
\end{aligned}
$$

Notice that the domestic and foreign discount factors load equally on the domestic and foreign stock return shocks, and their loadings on the exchange rate shock differ by exactly 
one. This drives the result (28). To complete the argument, just follow the algebra:

$$
\begin{aligned}
d \ln \Lambda^{f} & =-\left(r^{f}+\frac{1}{2} \mu^{f \prime} \Sigma^{-1} \mu^{f}\right) d t-\mu^{f \prime} \Sigma^{-1} d z \\
& =-\left(r^{f}+\frac{1}{2}\left(\mu^{d}-\Sigma^{e}\right)^{\prime} \Sigma^{-1}\left(\mu^{d}-\Sigma^{e}\right)\right) d t-\left(\mu^{d}-\Sigma^{e}\right) \Sigma^{-1} d z \\
& =-\left(r^{f}+\frac{1}{2} \mu^{d \prime} \Sigma^{-1} \mu^{d}-\mu^{d \prime} \Sigma^{-1} \Sigma^{e}+\frac{1}{2} \Sigma^{e \prime} \Sigma^{-1} \Sigma^{e}\right) d t-\mu^{d \prime} \Sigma^{-1} d z+d z^{e} \\
& =-\left(r^{f}+\frac{1}{2} \mu^{d \prime} \Sigma^{-1} \mu^{d}-\left(\theta^{e}+r^{f}-r^{d}\right)+\frac{1}{2} \Sigma^{e e}\right) d t-\mu^{d \prime} \Sigma^{-1} d z+d z^{e} \\
& =-\left(r^{d}+\frac{1}{2} \mu^{d \prime} \Sigma^{-1} \mu^{d}-\theta^{e}+\frac{1}{2} \Sigma^{e e}\right) d t-\mu^{d \prime} \Sigma^{-1} d z+d z^{e} \\
& =d \ln \Lambda^{d}-\left(-\theta^{e}+\frac{1}{2} \Sigma^{e e}\right) d t+d z^{e} \\
& =d \ln \Lambda^{d}+d \ln e .
\end{aligned}
$$

\section{Risk Sharing Index with Additional Risks}

Consider now a pair of arbitrary domestic and foreign discount factors $d \Lambda^{d *} / \Lambda^{d *}$ and $d \Lambda^{f *} / \Lambda^{f *}$ formed from the minimum-variance discount factors $d \Lambda^{d} / \Lambda^{d}$ and $d \Lambda^{f} / \Lambda^{f}$ by the addition of noises $d w^{d}$ and $d w^{f}$ with $\mathrm{E}\left(d w^{d} d z\right)=0$ and $\mathrm{E}\left(d w^{f} d z\right)=0$, respectively. Using these alternative discount factors, the risk sharing index is:

$$
1-\frac{\sigma^{2}\left(d \ln \Lambda^{d *}-d \ln \Lambda^{f *}\right)}{\sigma^{2}\left(d \ln \Lambda^{d *}\right)+\sigma^{2}\left(d \ln \Lambda^{f *}\right)} .
$$

To relate this expression to the risk sharing index using the minimum-variance discount factors, express $\ln \Lambda^{d *}=\ln \Lambda^{d}+\ln \eta^{d}$ from equation (25). Then:

$$
\begin{aligned}
d \ln \Lambda^{d *} & =d \ln \Lambda^{d}+d \ln \eta^{d} \\
& =d \ln \Lambda^{d}+\frac{1}{2} \sigma^{2}\left(d w^{d}\right) d t+d w^{d}
\end{aligned}
$$

where we use Ito's lemma on (26). There is a similar expression for the foreign discount factor. This implies that:

$$
\sigma^{2}\left(d \ln \Lambda^{d *}\right)=\sigma^{2}\left(d \ln \Lambda^{d}\right)+\sigma^{2}\left(d w^{d}\right)
$$

and

$$
\sigma^{2}\left(d \ln \Lambda^{d *}-d \ln \Lambda^{f *}\right)=\sigma^{2}\left(d \ln \Lambda^{d}-d \ln \Lambda^{f}\right)+\sigma^{2}\left(d w^{d}-d w^{f}\right) .
$$


Substituting the last two expressions into equation (32), the risk sharing index using the alternative discount factors is:

$$
\begin{aligned}
& 1-\frac{\sigma^{2}\left(d \ln \Lambda^{d}-d \ln \Lambda^{f}\right)+\sigma^{2}\left(d w^{d}-d w^{f}\right)}{\sigma^{2}\left(d \ln \Lambda^{d}\right)+\sigma^{2}\left(d \ln \Lambda^{f}\right)+\sigma^{2}\left(d w^{d}\right)+\sigma^{2}\left(d w^{f}\right)} \\
& =1-\frac{\Sigma^{e e}+\sigma^{2}\left(d w^{d}-d w^{f}\right)}{\mu^{d \prime} \Sigma^{-1} \mu^{d}+\mu^{f \prime} \Sigma^{-1} \mu^{f}+\sigma^{2}\left(d w^{d}\right)+\sigma^{2}\left(d w^{f}\right)} .
\end{aligned}
$$

We can now formalize the incomplete markets discussion in the introduction. If the "extra shocks" are the same across countries, $d w^{d}=d w^{f}$, then the numerator is unchanged and the denominator increases. Our risk sharing index therefore increases if the extra shocks are the same across countries. If the extra shocks have the same size but are uncorrelated, however, then $\sigma^{2}\left(d w^{d}-d w^{f}\right)=\sigma^{2}\left(d w^{d}\right)+\sigma^{2}\left(d w^{f}\right)$. The extra terms in the numerator and denominator are the same, which increases the ratio (since it starts below one) and pulls the risk sharing index towards zero. Note however that the denominator increases as well as the numerator. There must be more risk as well as less risk sharing, since we add uncorrelated components. Negatively correlated additional shocks drive the risk sharing index towards minus one while also increasing each country's overall risk.

\section{Results}

We implement the continuous time formulas in Section 2 with straightforward discrete time approximations and monthly data. We start with domestic excess stock returns $R_{t+\Delta}^{d}$, foreign excess stock returns $R_{t+\Delta}^{f}$, the exchange rate $e_{t}$ (in units of foreign currency per dollar), and domestic and foreign interest rates $r_{t+\Delta}^{d}$ and $r_{t+\Delta}^{f}$, where $\Delta=1 / 12$ years. With $\mathrm{E}_{T} \equiv \frac{1}{T} \sum_{t=1}^{T}$, we then estimate the instantaneous risk premia and variances required in the risk sharing measure (24) by the obvious sample counterparts to the continuous time moments:

$$
\begin{gathered}
\theta^{d}-r^{d}=\frac{1}{\Delta} \mathrm{E}_{T} R_{t+\Delta}^{d}, \quad \theta^{f}-r^{f}=\frac{1}{\Delta} \mathrm{E}_{T} R_{t+\Delta}^{f}, \\
\theta^{e}+r^{f}-r^{d}=\frac{1}{\Delta} \mathrm{E}_{T}\left(\frac{e_{t+\Delta}-e_{t}}{e_{t}}+r_{t+\Delta}^{f}-r_{t+\Delta}^{d}\right), \\
d z^{d}=R_{t+\Delta}^{d}-\mathrm{E}_{T} R_{t+\Delta}^{d}, \quad d z^{f}=R^{f}-\mathrm{E}_{T} R_{t+\Delta}^{f}, \\
d z^{e}=\left(\frac{e_{t+\Delta}-e_{t}}{e_{t}}\right)-\mathrm{E}_{T}\left(\frac{e_{t+\Delta}-e_{t}}{e_{t}}\right), \\
\Sigma=\frac{1}{\Delta} \mathrm{E}_{T}\left(d z d z^{\prime}\right) .
\end{gathered}
$$


We use real returns, real interest rates, and a real exchange rate, each adjusted ex-post by realized inflation. Since the risk sharing index is based entirely on excess returns, the calculation is fairly insensitive to how one handles interest rates and inflation. However, excess nominal returns are not quite the same as excess real returns, so we start with real returns to keep the calculation as pure as possible.

We use the US as the domestic country, and the UK, Germany, and Japan as the foreign countries. Table 1 presents summary statistics important to our calculation. The top panel shows the mean and standard deviation of the excess returns on the domestic and foreign stock indices and the exchange rate (annualized and reported in percent), and the bottom panel shows the correlations between the returns. (The excess return on the exchange rate is the return on borrowing domestically at the riskfree rate, converting to the foreign currency at the current exchange rate, lending at the foreign riskfree rate for one month, and then converting back to the domestic currency at the exchange rate prevailing at the end of the month.) Autocorrelation-corrected standard errors are in parentheses. ${ }^{17}$

The table reminds us of the high equity risk premium, not only in the US but also abroad. The mean excess stock index returns range from $4.78 \%$ in Japan to $10.31 \%$ in the UK and are all statistically significant. The standard deviation ranges from $14.70 \%$ in the US to $18.74 \%$ in Japan, resulting in annualized Sharpe ratios of 0.63 in the US, 0.57 in the UK, 0.43 in Germany, and 0.26 in Japan. The estimates of the exchange rate risk premium $\theta^{e}+r^{f}-r^{e}$ are positive for the UK and Germany and negative for Japan, but are all small and statistically indistinguishable from zero. The volatility of the exchange rates is almost as high as that for stocks, ranging from $11.51 \%$ to $12.89 \%$ (about the same magnitude as the volatility of long-term bond returns). The stock returns are positively correlated across countries, with correlations ranging from 0.34 to 0.57 , while the exchange rates are poorly correlated with stock return both in the US and abroad, with correlations less than 0.15 .

Table 1 also reminds us of how difficult it is to estimate equity risk premia. For example, the US risk premium of $9.21 \%$ is measured with a $2.81 \%$ standard error. The reason is, of course, the high volatility of stock returns relative to the size of the mean return. The standard error of the mean return $\sigma\left(R_{t+\Delta}\right) / \sqrt{T}$, and its more precise incarnation in our GMM standard errors, dooms precise measurement of the risk premium. This is the central source of uncertainty in the risk sharing index.

Using these return moments and the average ex-post real one-month interest rate to proxy for the real riskfree rate in each country, we compute the minimum-variance domestic and

${ }^{17}$ To obtain standard errors, we stack equations (37) into a vector of moment conditions and treat that vector in the framework of GMM estimation (Hansen, 1982). We use Newey and West's (1987) estimator of the moment covariance matrix with a six-month correction for serial correlation. 
foreign discount factors for the three country pairs (i.e., US versus UK, US versus Germany, and US versus Japan) from equations (16) and (22). Figure 1 plots these discount factors to obtain a visual idea of their correlation. On the left, we plot the logarithms of the levels of US and foreign marginal utility. On the right, we show a scatter plot of the US versus foreign marginal utility growths. As the pictures show, the US and foreign marginal utility growths are nearly the same. They do differ, by the exchange rate, but marginal utility growth is so volatile relative to the exchange rate that they do not differ by much. Therefore, domestic and foreign marginal utility growths are very close. This is our basic point.

Table 2 calculates the volatilities of the minimum-variance domestic and foreign discount factors. These volatilities have the interpretation of the maximum Sharpe ratios obtainable by trading in the international assets. We see that the maximum Sharpe ratios are of the order of 0.63 to 0.69 , and are very similar for investors in each pair of countries. The reason for this similarity is that all investors essentially have the same set of assets available to them, with the only distortion caused by the exchange rate volatility. (US investors take on exchange rate risk to invest abroad and the opposite for foreign investors.) For the observed exchange rate volatilities, this distortion is very small. If exchange rates were more volatile, the discount factor volatilities would differ more across countries.

Table 2 also presents our central result, the risk sharing index (24). The numbers are all at or above 0.98 , implying a very high level of international risk sharing. This result is driven by the relatively low volatilities of the exchange rates compared to the volatilities of marginal utility growth. The risk sharing index for Japan is the lowest, with a value of 0.98, reflecting the lower volatilities of marginal utility growth (due to the lower equity risk premium in Japan) and the higher exchange rate volatility.

The standard errors on the volatilities of marginal utility growth are quite high, ranging from 0.13 to 0.21 . This is because the variance of marginal utility growth depends on the mean excess returns $\mu^{d}$ and $\mu^{f}$ (see equation (18)), which, as we saw in Table 1, are difficult to estimate precisely. However, the standard errors on the risk sharing index are very small. The risk sharing index of 0.98 is measured with a standard error of about 0.01 . The index is so close to one that even substantial uncertainty about the volatility of marginal utility growth does not much affect its value. Even if the variance of marginal utility growth were $20 \%$ lower, the risk sharing index would still be 0.96 .

To explore in more detail the effect of uncertainty about the equity risk premium on our calculation, we report in Table 3 the risk sharing index for different equity premia. There is no point in redoing the experiment for all three countries, so we use a simple set of representative numbers for this and following experiments. We use a stock excess return 
volatility of $18 \%$ for both countries. We set the exchange rate volatility to $12 \%$. We assume a correlation of 0.4 between the stock indices and zero correlation between the stock indices and the exchange rate. We set the domestic exchange rate risk premium to zero. ${ }^{18}$ Our baseline is a stock excess return premium of $8 \%$ in each country. In the notation of the formulas, our assumptions for the sensitivity analyses are:

$$
\begin{gathered}
\theta^{e}+r^{f}-r^{e}=0, \quad \theta^{d}-r^{d}=\theta^{f}-r^{f}=0.08 \\
\sigma\left(d z^{d}\right)=\sigma\left(d z^{f}\right)=0.18, \quad \sigma\left(d z^{e}\right)=0.12 \\
\rho\left(d z^{d}, d z^{f}\right)=0.4, \quad \rho\left(d z^{d} d z^{e}\right)=\rho\left(d z^{f} d z^{e}\right)=0 .
\end{gathered}
$$

The risk sharing index for these parameter values is 0.98 , just as in the data. For Table 3, we vary the domestic and foreign equity risk premia $\theta^{d}-r^{d}$ and $\theta^{f}-r^{f}$ from $2 \%$ to $10 \%$ and report the corresponding values of the risk sharing index.

You may distrust the 1975-1998 sample period and suspect that our surprisingly high risk sharing index is driven by an abnormally high equity risk premium in that period. However, Table 3 shows that even a $6 \%$ equity risk premium, rather than the $9 \%$ estimate for the US, still produces a risk sharing index of 0.97 . Even a very low $4 \%$ equity risk premium in both countries implies a risk sharing index of 0.91 . (We focus on equity risk premia below $8 \%$ based on our own priors that this sample premium represents some good luck. Also, parameters that potentially lower an 0.98 index are more interesting than parameters that potentially raise it even closer to one.)

Table 3 also shows that the risk sharing index is driven by the larger of the domestic and foreign equity risk premia. As long as one of the risk premia is high, above $6 \%$ say, the risk sharing index is also high, above 0.96. Only when both premia drop below $4 \%$ does the risk sharing index decrease substantially. The risk sharing index is driven by the maximum Sharpe ratio in portfolios of the domestic and international assets. As long as the Sharpe ratio in one of the countries is high and the exchange rate is not too volatile, the internationally obtainable Sharpe ratio is also high.

This fact contributes to the small standard errors of our risk sharing index in Table 2. To see much difference in the risk sharing index, not only one, but both equity risk premia must be much smaller than they appear in sample (below 4\%).

To get a better sense for the marginal utility growths recovered from asset markets, we show in Table 4 the (negative of the) loadings $\mu^{d \prime} \Sigma^{-1}$ and $\mu^{f \prime} \Sigma^{-1}$ of the domestic and foreign

\footnotetext{
${ }^{18}$ This assumption gives foreigners a currency risk premium of $-\Sigma^{e e} \approx 0.1^{2}=1 \%$. However, the results are all driven by the equity risk premia and are very insensitive to the assumed exchange rate risk premium.
} 
discount factors on the excess return shocks $d z$. As we showed in equation (30), the discount factor loadings on the stock return shocks are exactly the same, and the foreign discount factor loads by minus one more on the exchange rate shock, so that the difference between the two discount factors is exactly equal to the exchange rate. Also sensibly, the loadings on the stock market shocks are all positive, which, together with the minus sign in equations (16) and (22), means that marginal utility declines when either stock market rises. Finally, since the weights are larger on the stocks than on the exchange rate, the volatility in marginal utility growth comes mostly from stock market shocks.

Risk sharing measures based on consumption data typically show much less risk and much worse risk sharing. To examine the discrepancy between our asset market view of risk sharing and consumption data, we calculate discount factors and risk sharing measures implied by consumption data and standard power utility.

Table 5 shows annualized standard deviations and correlations of log consumption growth for the three country pairs. Since high frequency consumption data is notoriously noisy, we consider both quarterly and annual data. (Temporally aggregating consumption data is likely to reduce the effect of measurement errors. See Bell and Wilcox, 1993, and Wilcox, 1992.) The table confirms the usual results. Consumption growth is very smooth, with standard deviations of $1.4 \%$ to $3.1 \%$. Using CRRA utility with $u^{\prime}(c)=c^{-\gamma}$, log marginal utility growth is $d \ln \Lambda=\gamma d \ln c$. As is well known from the equity risk premium literature, we therefore need a very large $\gamma$, at least 20, to generate from this smooth consumption the $60 \%$ volatility of marginal utility growth implied by asset markets in Table 2.

Table 5 also shows that consumption growth is far from perfectly correlated across countries, with correlations ranging from 0.17 to 0.42 . The correlations are highest between the US and UK and lowest between the US and Germany. Although an outsider might find these correlations reasonably high, they are not one, which is the heart of the puzzle that international risks do not seem to be perfectly shared (see Obsfeld and Rogoff, 2000).

Assuming for simplicity that the domestic and foreign representative investors have the same level of relative risk aversion, we can compute the risk sharing index as: ${ }^{19}$

$$
1-\frac{\sigma^{2}\left(d \ln \Lambda^{d}-d \ln \Lambda^{f}\right)}{\sigma^{2}\left(d \ln \Lambda^{d}\right)+\sigma^{2}\left(d \ln \Lambda^{f}\right)}=1-\frac{\sigma^{2}\left(d \ln c^{d}-d \ln c^{f}\right)}{\sigma^{2}\left(d \ln c^{d}\right)+\sigma^{2}\left(d \ln c^{f}\right)} .
$$

Notice that the risk aversion coefficients drop out of the index when both countries have the same level of risk aversion. As shown in Table 5, this calculation results in a risk sharing

\footnotetext{
${ }^{19}$ In incomplete markets, consumption-based discount factors are not related by equation (28), so we cannot use exchange rates in the numerator of the risk sharing index.
} 
index of 0.17 to 0.36 . These are much lower than what is implied by asset markets, and they capture in our index the usual conclusion that risks are poorly shared internationally. (The index is lower than the consumption growth correlation because the index penalizes size as well as correlation. The greater standard deviation of foreign consumption growth would count against risk sharing even if consumption growths were perfectly correlated.)

How much non-market risk would it take to drive the asset market based risk sharing index down to the values suggested by consumption data and power utility? Table 6 investigates this question quantitatively. (Of course, this calculation will add to the total discount factor volatility, so we cannot consider it a reconciliation of consumption and asset market views, but it is still worth making.) Similar to the experiment in Table 3, start with the parameter values (38). We then vary the volatility of the additional risks $d w^{d}$ and $d w^{f}$ from zero to $40 \%$ and the correlation between them from minus one to plus one. The table reports the corresponding values of the risk sharing index, calculated from equation (36).

If we assume that the extra risks are uncorrelated (a reasonable assumption), the volatility of extra risks has to be more than $40 \%$ to reduce the risk sharing index to below 0.7 (which is not even close to the 0.3 implied by consumption data). In this calculation, the minimumvariance marginal utility growth already has a standard deviation of $57 \%$, so we have to add unspanned risks of the same magnitude to see a substantial reduction in risk sharing. Since the volatility of marginal utility growth is already a famous puzzle, another set of risks of the same magnitude, uncorrelated with market returns, seems excessive.

Omitted assets and international business cycles are likely to induce a positive correlation between the extra risks. Table 6 shows that a positive correlation slows down the rate at which the index decreases with the volatility of the extra risks. For example, with correlation of 0.8 , the risk sharing index with $40 \%$ volatility of unspanned risks is still 0.92 . As explained in the introduction, with a perfect correlation, the index increases as we add extra risks.

A negative correlation between the unspanned risks across countries brings down the risk sharing index more quickly. (There is little reason to think that the extra risks are negatively correlated, except perhaps due to beggar-thy-neighbor policies.) With a correlation of -0.8, for example, a 0.5 risk sharing index can be obtained with slightly more than $30 \%$ volatility of extra risks. With an extra $50 \%$ volatility, the index is in the neighborhood of the numbers implied by consumption data. (However, we then need risk aversion of 35 to 40 to reconcile the consumption data with the inflated volatility of marginal utility growth.)

In sum, though overall risks can be better or worse shared than our index, substantially worse risk sharing does not seem quantitatively plausible. One has to believe in a lot of extra 
risks, or have those risks strongly negatively correlated across countries, to generate overall risk sharing close to the traditional values inferred from consumption data.

Suppose that risks are in fact not well shared internationally. Then, the exchange rates are surprisingly smooth. To make this point quantitatively, we solve in Table 7 for the exchange rate volatility that is consistent with a risk sharing index of 0.35 (the highest value implied by the consumption data). As in Table 3, we start with the parameters (38) and vary the domestic and foreign equity risk premia $\theta^{d}-r^{d}$ and $\theta^{f}-r^{f}$ from $4 \%$ to $8 \%$. (Since our index is driven by the maximum risk premium, we set $\theta^{d}-r^{d}=\theta^{f}-r^{f}$.) The standard deviation of the implied minimum-variance discount factors ranges from $28 \%$ to $57 \%$. As in Table 6, we then add to these minimum-variance discount factors unspanned risks $d w^{d}$ and $d w^{f}$ with volatilities ranging from zero to $40 \%$ and a correlation of either zero and 0.4. Table 7 reports the exchange rate volatilities that makes equation (36) evaluate to 0.35 .

Table 7 shows that for equity risk premia of $6 \%$ to $8 \%$ (still lower than our estimates), the exchange rate volatility should at least be about $40 \%$, and closer to $60 \%$ for most specifications. While unspanned risks lower the implied exchange rate volatility somewhat, since they make discount factors less correlated for given exchange rates, even $40 \%$ extra risks are not in the ballpark to get down to a $10 \%$ exchange rate volatility. Only when the risk premia are as low as $4 \%$ and the extra risks are uncorrelated (or negatively correlated) with more than $35 \%$ volatility does the implied exchange rate volatility drop to its historical level. However, to evaluate whether this is a realistic scenario, notice that the extra risks are more than 1.25 times as volatile as the minimum variance discount factor (with a standard deviation of $28 \%$ ). This means that less than $40 \%$ of all risks are spanned by the traded assets, which is clearly an extreme amount of market incompleteness.

\section{Conclusion}

We present an asset markets view of international risk sharing. The high Sharpe ratios obtainable in international asset markets imply that marginal utility growth is very volatile for both the domestic and foreign country - there is a lot of risk to share. Compared to this volatility, the volatility of exchange rates is very small. Since the exchange rate between two countries is the only difference between their marginal utility growths, we therefore conclude that there is a surprisingly high level of international risk sharing. Alternatively, if risks

really are poorly shared, exchange rates are much too smooth. Both conclusions are in stark contrast to the standard findings from consumption data.

Since markets are incomplete, our risk-sharing index answers the question, "To what 
extent do exchange rate movements blunt the risk-sharing possibilities of existing asset markets?" The answer is "not much," and "there is a lot of risk to be shared." Risks that induce marginal utility movements uncorrelated with asset payoffs can lower overall risk sharing, but we argue that reasonably sized and correlated risks cannot lower overall risk sharing by much.

We conducted our analysis only for country pairs and two assets in each country - the stock market and a riskfree asset. Taking into account more countries at once and more assets will make our results even stronger since the maximum Sharpe ratio obtainable in international asset markets can only increase. Furthermore, adding conditioning information is likely to increase the implied level of risk sharing as well. For example, Brandt and SantaClara (2001) find that the volatility of exchange rates drops at times very significantly, which means even higher values of the risk sharing index at those times (holding fixed the volatilities of marginal utility growth). 


\section{References}

Backus, David K., Silverio Foresi, and Chris I. Telmer, 2001, Affine term structure models and the forward premium anomaly, Journal of Finance 56, 279-304.

Backus, David K., Patrick J. Kehoe, and Finn E. Kydland, 1992, International real business cycles, Journal of Political Economy 100, 745-755.

Backus, David K., and Gregor W. Smith, 1993, Consumption and real exchange rates in dynamic economies with non-traded goods, Journal of International Economics 35, 297316.

Baxter, Marianne, and Urban J. Jermann, 1997, The international diversification puzzle is worse than you think, American Economic Review 87, 170-191.

Baxter, Marianne, Urban J. Jermann, and Robert King, 1995, Nontraded goods, nontraded factors, and international nondiversification, Journal of International Economics 46, 211229.

Bell, William R., and David W. Wilcox, 1993, The effect of sampling error on the time series behavior of consumption data, Journal of Econometrics 55, 235-265.

Black, Fischer, and Robert Litterman, 1992, Global portfolio optimization, Financial Analysts Journal 48, 28-43.

Brandt, Michael W., and Pedro Santa-Clara, 2001, Simulated likelihood estimation of diffusions with an application to exchange rate dynamics in incomplete markets, Journal of Financial Economics, forthcoming.

Brennan, Michael J., and Bruno Solnik, 1989, International risk sharing and capital mobility, Journal of International Money and Finance 8, 359-373.

Campbell, John Y., 1999, Asset prices, consumption, and the business cycle, in J. Taylor and M. Woodford, eds., Handbook of Macroeconomics, Volume 1, North-Holland: Amsterdam.

Campbell, John Y., and John H. Cochrane, 1999, By force of habit: A consumption-based explanation of aggregate stock market behavior, Journal of Political Economy 107, 205251.

Cochrane, John H., 1991, A simple test of consumption insurance, Journal of Political Economy 99, 957-976.

Cochrane, John H., 2001, Asset Pricing, Princeton University Press: Princeton, NJ.

Cochrane, John H., and Jesús Saá-Requejo, 2000, Beyond arbitrage: Good-deal asset price bounds in incomplete markets, Journal of Political Economy 108, 79-119.

Constantinides, George M., and Darrell Duffie, 1996, Asset pricing with heterogeneous consumers, Journal of Political Economy 104, 219-240. 
Coval, Joshua D., and Tobias J. Moskowitz, 1999, Home bias at home: Local equity preference in domestic portfolios, Journal of Finance 54, 2045-2074.

Dumas, Bernard, Campbell R. Harvey, and Pierre Ruiz, 2000, Are correlations of stock returns justified by subsequent changes in national outputs?, Working Paper, INSEAD.

Flood, Robert P., and Andrew K. Rose, 1995, Fixing the exchange rate regime: A virtual quest for fundamentals, Journal of Monetary Economics 36, 3-37.

French, Kenneth, and James Poterba, 1991, Investor diversification and international equity markets, American Economic Review 81, 222-226.

Hansen, Lars Peter, 1982, Large sample properties of generalized method of moments estimators, Econometrica 50, 1029-1054.

Hansen, Lars Peter, and Ravi Jagannathan, 1991, Implications of security market data for models of dynamic economies, Journal of Political Economy 99, 225-262.

Lewis, Karen K., 1996, What can explain the lack of international consumption risk sharing?, Journal of Political Economy 104, 267-297.

Lewis, Karen K. 1999, Trying to explain home bias in equities and consumption, Journal of Economic Literature 37, 571-608.

Lewis, Karen K., 2000, Why do stocks and consumption imply such different gains from international risk sharing?, Journal of International Economics 52, 1-35.

Mace, Barbara, 1991, Full insurance in the presence of aggregate uncertainty, Journal of Political Economy 99, 928-956.

Meese, Richard, and Kenneth Rogoff, 1983, Empirical exchange rate models of the seventies: Do they fit out of sample?, Journal of International Economics 14, 3-24.

Nelson, Mark, 1985, Exchange rates and fundamentals: Evidence on long-horizon predictability, American Economic Review 85, 201-218.

Newey, Whitney K., and Kenneth D. West, 1987, A simple, positive semi-definite, heteroscedasticity and autocorrelation consistent covariance matrix, Econometrica 55, $703-708$.

Nielsen, Lars Tyge, and Jesús Saá-Requejo, 1993, Exchange rate and term structure dynamics and the pricing of derivative securities, Working Paper, INSEAD.

Obsfeld, Maurice, and Kenneth Rogoff, 2000, The six major puzzles in international macroeconomics: Is there a common cause?, in B. Bernanke and K. Rogoff, eds., NBER Macroeconomics Annual, MIT Press: Cambridge, MA.

Rogoff, Kenneth, 1999, Perspectives on exchange rate volatility, in M. Feldstein, eds., International Capital Flows, University of Chicago Press: Chicago, IL. 
Saá-Requejo, Jesús, 1993, The dynamics and the term structure of risk premia in the foreign exchange markets, Working Paper, University of Chicago.

Solnik, Bruno H., 1974, Why not diversify internationally rather than domestically?, Financial Analysts Journal 30, 48-54.

Tesar, Linda L., 1993, International risk-sharing and non-traded goods, Journal of International Economics 35, 69-89.

Tesar, Linda L., and Ingrid M. Werner, 1995, Home bias and high turnover, Journal of International Money and Finance 14, 467-92.

Wilcox, David W., 1992, The construction of U.S. consumption data: Some facts and their implications for empirical work, American Economic Review 82, 922-941. 
Table 1: Summary Statistics

\begin{tabular}{|c|c|c|c|c|c|c|c|}
\hline & \multirow[b]{2}{*}{ US Stock } & \multicolumn{2}{|c|}{ UK } & \multicolumn{2}{|c|}{ Germany } & \multicolumn{2}{|c|}{ Japan } \\
\hline & & Stock & X-Rate & Stock & X-Rate & Stock & X-Rate \\
\hline & \multicolumn{7}{|c|}{ Returns (\%) } \\
\hline Mean & $\begin{array}{c}9.21 \\
(2.81)\end{array}$ & $\begin{array}{l}10.31 \\
(1.69)\end{array}$ & $\begin{array}{c}0.16 \\
(2.69)\end{array}$ & $\begin{array}{c}7.21 \\
(1.59)\end{array}$ & $\begin{array}{l}1.75 \\
(3.01)\end{array}$ & $\begin{array}{c}4.78 \\
(1.46)\end{array}$ & $\begin{array}{l}-0.84 \\
(2.85)\end{array}$ \\
\hline \multirow[t]{2}{*}{ Std Dev } & $\begin{array}{l}14.70 \\
(0.09)\end{array}$ & $\begin{array}{l}18.12 \\
(0.17)\end{array}$ & $\begin{array}{l}11.51 \\
(0.03)\end{array}$ & $\begin{array}{l}16.65 \\
(0.12)\end{array}$ & $\begin{array}{l}11.56 \\
(0.03)\end{array}$ & $\begin{array}{l}18.74 \\
(0.17)\end{array}$ & $\begin{array}{l}12.89 \\
(0.04)\end{array}$ \\
\hline & \multicolumn{7}{|c|}{ Return Correlations } \\
\hline $\begin{array}{c}\text { US Stock } \\
\text { Foreign Stock }\end{array}$ & & 0.57 & $\begin{array}{l}0.01 \\
0.04\end{array}$ & 0.45 & $\begin{array}{l}0.01 \\
0.13\end{array}$ & 0.34 & $\begin{array}{r}0.03 \\
-0.08\end{array}$ \\
\hline
\end{tabular}

This table shows annualized summary statistics for real excess returns on stock indices and exchange rates for the US, UK, Germany, and Japan. The stock indices are total market returns from Datastream, the interest rates are for one-month Eurocurrency deposits from Datastream, and the CPI is from the International Monetary Fund's IFS database. The stock returns (Stock) are excess returns over the one-month interest rates. The exchange rate returns (X-rate) are excess returns for borrowing domestically, converting to the foreign currency, lending at the foreign interest rate, and converting the proceeds back to the domestic currency. Monthly data from January 1975 through June 1998. Serial-correlation adjusted standard errors in parenthesis. 
Table 2: Risk Sharing Index

\begin{tabular}{cccc}
\hline & US vs UK & US vs Germany & US vs Japan \\
\hline \multirow{4}{*}{ Domestic } & \multicolumn{2}{c}{ Std Dev of Marginal Utility } & Growth \\
\cline { 2 - 4 } Foreign & 0.686 & 0.671 & 0.635 \\
& $(0.182)$ & $(0.182)$ & $(0.205)$ \\
& 0.686 & 0.654 & 0.665 \\
& $(0.134)$ & $(0.187)$ & $(0.164)$ \\
& \multicolumn{4}{c}{ Risk Sharing Index } \\
\cline { 2 - 4 } & 0.986 & 0.985 & 0.980 \\
& $(0.005)$ & $(0.007)$ & $(0.016)$ \\
\hline
\end{tabular}

This table shows annualized standard deviations of the discount factors recovered from asset markets and the corresponding risk sharing indices. The domestic country is the US and the foreign country is the UK, Germany, or Japan. The investable assets are the domestic interest rate, the domestic stock market, the foreign interest rate, and the foreign stock market. The discount factors are given in equations (16) and (22). The risk sharing index is defined in equation (24). Serial-correlation adjusted standard errors in parenthesis. 
Table 3: How the Risk Sharing Index Depends on Equity Risk Premia

\begin{tabular}{rccccc}
\hline & \multicolumn{5}{c}{$\theta^{f}-r^{f}$} \\
\cline { 2 - 6 }$\theta^{d}-r^{d}$ & $2 \%$ & $4 \%$ & $6 \%$ & $8 \%$ & $10 \%$ \\
\hline $2 \%$ & 0.740 & 0.880 & 0.941 & 0.966 & 0.977 \\
$4 \%$ & & 0.911 & 0.945 & 0.966 & 0.978 \\
$6 \%$ & & & 0.957 & 0.970 & 0.978 \\
$8 \%$ & & & & 0.975 & 0.981 \\
$10 \%$ & & & & & 0.984
\end{tabular}

This table calculates the risk sharing index for different values of the mean excess returns of the domestic stock market $\theta^{d}-r^{d}$ and foreign stock market $\theta^{f}-r^{f}$. The volatility of the exchange rate is $12 \%$. The volatility of both stock indices is $18 \%$. The correlation between the stock returns is 0.4 and the stock returns are both uncorrelated with the exchange rate. The domestic exchange rate risk premium $\theta^{e}+r^{f}-r^{d}$ is zero. 
Table 4: Discount Factor Loadings

\begin{tabular}{|c|c|c|c|c|c|c|}
\hline & \multicolumn{2}{|c|}{ US vs UK } & \multicolumn{2}{|c|}{ US vs Germany } & \multicolumn{2}{|c|}{ US vs Japan } \\
\hline & Domestic & Foreign & Domestic & Foreign & Domestic & Foreign \\
\hline$d z^{d}$ & 3.126 & 3.126 & 3.768 & 3.768 & 4.220 & 4.220 \\
\hline$d z^{e}$ & 0.307 & -0.693 & 1.049 & 0.049 & -0.755 & -1.755 \\
\hline$d z^{f}$ & 1.731 & 1.731 & 1.131 & 1.131 & 0.136 & 0.136 \\
\hline
\end{tabular}

This table shows the loading of the discount factors $\mu^{d \prime} \Sigma^{-1}$ and $\mu^{f \prime} \Sigma^{-1}$ on the domestic stock return shocks $d z^{d}$, the exchange rate shocks $d z^{e}$ and the foreign stock return shocks $d z^{f}$. The risk premium vectors $\mu^{d}$ and $\mu^{f}$ are given in equation (15) and (21). 


\section{Table 5: Risk Sharing Index From Consumption Data}

\begin{tabular}{cccc}
\hline & US vs UK & US vs Germany & US vs Japan \\
\hline & \multicolumn{3}{c}{ Std Dev of Log Consumption Growth (\%) } \\
\cline { 2 - 4 } Quarterly: & & & \\
Domestic & 1.44 & 1.44 & 1.44 \\
Foreign & 3.11 & 1.66 & 2.65 \\
Annual: & & & \\
Domestic & 1.80 & 1.80 & 1.80 \\
Foreign & 3.14 & 2.09 & 1.58 \\
& Log Consumption Growth Correlations \\
\cline { 2 - 4 } Quarterly & 0.31 & 0.17 & 0.27 \\
Annual & 0.42 & 0.24 & 0.35 \\
& \multicolumn{4}{c}{0.166} \\
Quarterly & 0.245 & Risk Sharing Index \\
Annual & 0.361 & 0.233 & 0.350 \\
\hline
\end{tabular}

This table shows annualized summary statistics for domestic and foreign log consumption growth and the corresponding risk sharing index. Consumption is real per-capita consumption of nondurables and services from the International Monetary Fund's IFS database. Quarterly and annual data from Q1 1975 through Q2 1998. Quarterly standard deviations are annualized. The domestic country is the US and the foreign country is the UK, Germany, or Japan. The risk sharing index is calculated according to equation (39). 
Table 6: Risk Sharing Index with Incomplete Markets

\begin{tabular}{cccccc}
\hline & \multicolumn{5}{c}{$\sigma\left(d w^{d}\right)=\sigma\left(d w^{f}\right)$} \\
\cline { 2 - 6 }$\rho\left(d w^{d}, d w^{f}\right)$ & $0 \%$ & $5 \%$ & $10 \%$ & $20 \%$ & $40 \%$ \\
\hline-1.0 & 0.978 & 0.963 & 0.920 & 0.763 & 0.330 \\
-0.8 & 0.978 & 0.965 & 0.926 & 0.785 & 0.395 \\
-0.4 & 0.978 & 0.974 & 0.961 & 0.915 & 0.789 \\
0.0 & 0.978 & 0.971 & 0.949 & 0.872 & 0.658 \\
0.4 & 0.978 & 0.974 & 0.961 & 0.915 & 0.789 \\
0.8 & 0.978 & 0.977 & 0.973 & 0.959 & 0.920 \\
1.0 & 0.978 & 0.978 & 0.979 & 0.980 & 0.985 \\
\hline
\end{tabular}

This table shows the risk sharing index in the case of incomplete markets for different levels of the volatility and correlation of additional risks. The domestic and foreign mean excess stock returns $\theta^{d}-r^{d}$ and $\theta^{f}-r^{f}$ are $8 \%$. The volatility of both stock returns is $18 \%$. The volatility of the exchange rate is $12 \%$. The correlation between the stock returns is 0.4 and the stock returns are both uncorrelated with the exchange rate. The domestic foreign exchange risk premium $\theta^{e}+r^{f}-r^{d}$ is zero. The implied standard deviation of the minimum-variance discount factors is $56.7 \%$. The risk sharing index is given in equation (36). 
Table 7: Exchange Rate Volatility Implied by a Risk Sharing Index of 0.35

\begin{tabular}{cccccc}
\hline & \multicolumn{5}{c}{$\sigma\left(d w^{d}\right)=\sigma\left(d w^{f}\right)$} \\
\cline { 2 - 6 }$\mu^{d}=\mu^{f}$ & $0 \%$ & $10 \%$ & $20 \%$ & $30 \%$ & $40 \%$ \\
\hline \multicolumn{5}{c}{$\rho=0.0$} \\
$4 \%$ & 33.7 & 32.7 & 29.3 & 22.5 & 4.2 \\
$6 \%$ & 49.4 & 48.7 & 46.5 & 42.6 & 36.4 \\
$8 \%$ & 65.3 & 64.8 & 63.2 & 60.3 & 56.1 \\
& \multicolumn{5}{c}{$\rho=0.4$} \\
$4 \%$ & 33.7 & 33.9 & 34.3 & 35.0 & 36.0 \\
$6 \%$ & 49.4 & 49.5 & 49.8 & 50.3 & 51.0 \\
$8 \%$ & 65.3 & 65.4 & 65.6 & 66.0 & 66.5 \\
\cline { 2 - 6 }
\end{tabular}

This table shows the exchange rate volatility implied by a risk sharing index of 0.35 in the case of incomplete markets for different levels of the domestic and foreign mean excess stock returns $\theta^{d}-r^{d}$ and $\theta^{f}-r^{f}$ and different levels of the volatility and correlation of additional risks. The volatility of both stock returns is $18 \%$. The volatility of the exchange rate is $12 \%$. The correlation between the stock returns is 0.4 and the stock returns are both uncorrelated with the exchange rate. The domestic foreign exchange risk premium $\theta^{e}+r^{f}-r^{d}$ is zero. The implied standard deviations of the minimum-variance discount factors are $28.3 \%, 42.5 \%$, and $56.7 \%$. The implied exchange rate volatility is computed by setting equation (36) equal to 0.35 . 
Figure 1: Discount Factors
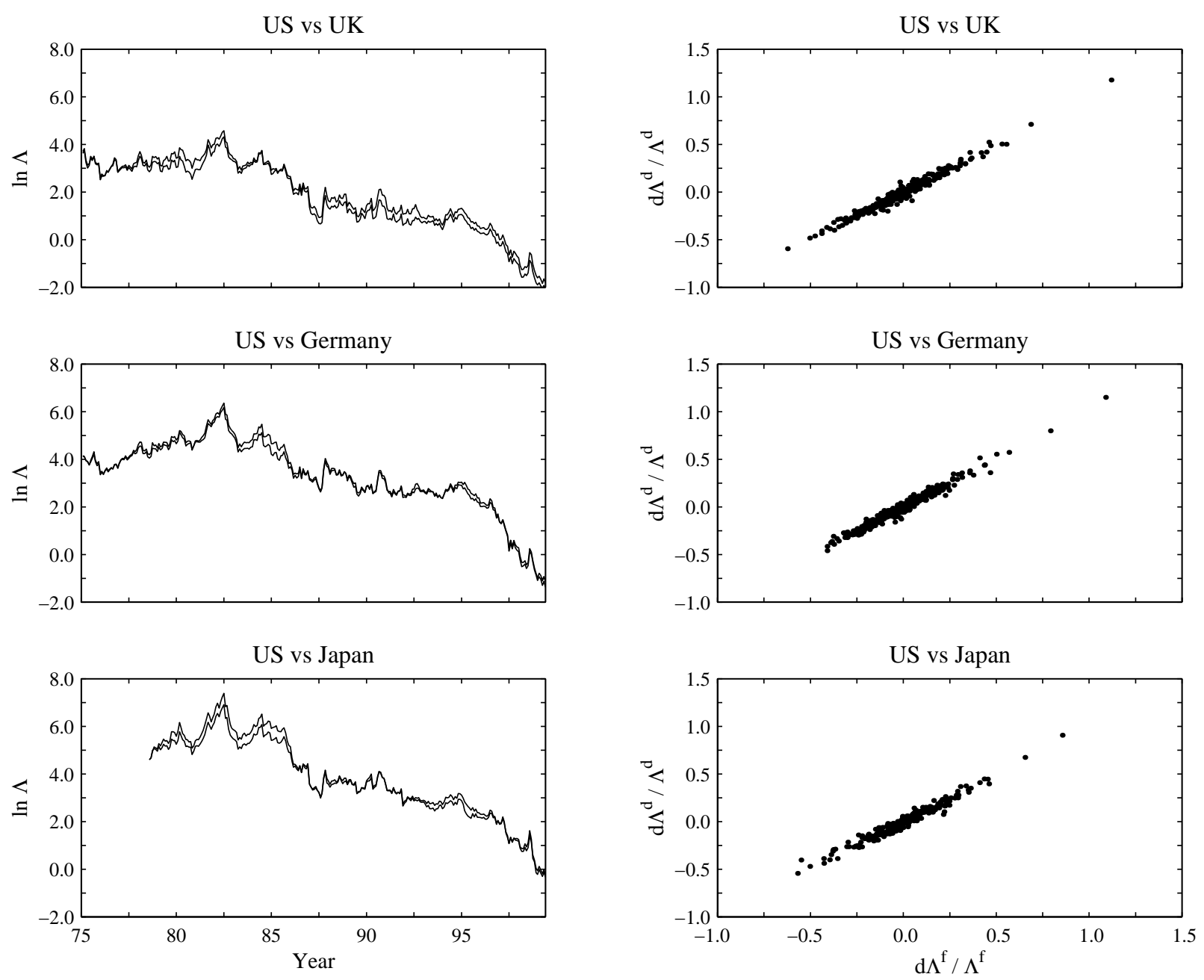

This figure presents discount factors implied by asset markets, both in levels and in percent differences. The US is the domestic country and the UK, Germany, and Japan are the foreign country. The investable assets are the domestic riskfree rate and stock market as well as the foreign riskfree rate and stock market. The discount factors are given in (16) and (22). 